Dermatology 2016;232:521

DOI: $10.1159 / 000448246$

\section{Phenotypic Characterization of Patients with Hidradenitis Suppurativa}

Dan Lipsker ${ }^{\mathrm{a}}$, Jean Revuz ${ }^{\mathrm{b}}$

${ }^{a}$ Clinique Dermatologique, Faculté de Médecine, Université de Strasbourg, Strasbourg, and ${ }^{b}$ Private practice, Paris, France

Key Words

Hidradenitis suppurativa - Phenotype characterization . Imaging

We thank Dr. Wortsman for her valuable comments [1] about our publications [2-4] on the terminology of clinical lesions in patients with hidradenitis suppurativa (HS).

She provides important information about her experience with ultrasound imaging in patients with HS.

She discusses the fact that nodules, cords and tunnels can actually be the clinical manifestation of various types of lesions from an anatomical and/or imaging point of view.

That is absolutely right, and this is why our work was performed. It is indeed an important necessity in the clinical description of patients with HS to switch from nosological terms such as 'abscess', 'boils', or 'scarring' to descriptive terms with standardized definitions that do not suppose any underlying mechanism. From a morphological and descriptive dermatological point of view, terms such as 'nodule' or 'cord' fulfill this purpose. As we have shown in a previous work [5], unfortunately in the vast majority of publications devoted to HS, clinicians still use nosological terms in their description, and Dr. Wortsman is correct when she points to the fact that it is often impossible from a simple clinical evaluation to correctly identify the underlying pathological pro- cess. Thus, nosological terms, which involve interpretation of clinical findings, should be avoided in the description, and we should only use simple descriptive terms.

Our first step is to have a consensus among clinicians about the terminology used and a clear clinical description of what is called a nodule, a sinus tract, a cord.... At the moment this is not the case.

The next step will be to establish a correlation between clearly defined clinical lesions, imaging studies and anatomical findings. In this regard, Dr. Wortsman's experience with ultrasound imaging in $\mathrm{HS}$ is valuable. And as she points to the existence of subclinical anatomical lesions (pseudocyst, fluid collection, fistulous tract) in patients with HS that have been described only by imaging, the integration of systematic imaging techniques in the exact staging of HS could be of an important added value. Those techniques have so far been restricted to the field of clinical research in most countries. Their utility in daily practice and how they can affect treatment strategies must still be evaluated. But they are for sure already an added value to better characterize the different phenotypes of HS encountered in clinical practice.

Disclosure Statement

The authors have no conflicts of interest to disclose.

\section{References}

1 Wortsman X: Reply to Lipsker et al. and Revuz on hidradenitis suppurativa terminology: the imaging point of view. Dermatology 2016;232:520.

-2 Lipsker D, Severac F, Freysz M, Sauleau E, Boer J, Emtestam L, Matusiak Ł, Prens E, Velter C, Lenormand C, Meyer N, Jemec GB: The ABC of hidradenitis suppurativa: a validated glossary on how to name lesions. Dermatology 2016;232:137-142.

3 Revuz J: Hidradenitis suppurativa: terminology. Dermatology 2016;232: 381.

4 Lipsker D: Reply to Revuz' letter entitled 'Hidradenitis suppurativa: terminology'. Dermatology 2016;232:382.

5 Freysz M, Jemec GB, Lipsker D: A systematic review of terms used to describe hidradenitis suppurativa. Br J Dermatol 2015;173:1298-1300.

\section{KARGER}

E-Mail karger@karger.com

www.karger.com/drm
(2) 2016 S. Karger AG, Base

$1018-8665 / 16 / 2324-0521 \$ 39.50 / 0$
Dan Lipsker

Clinique Dermatologique, Faculté de Médecine

Université de Strasbourg, 1, place de l'hôpital

FR-67091 Strasbourg (France)

E-Mail dan.lipsker@chru-strasbourg.fr 